\title{
MASSA DE FORRAGEM E COMPOSIÇÃO QUÍMICO- BROMATOLÓGICA DE Panicum maximum cv. mombaça ADUBADAS COM RESÍDUO DE SIDERURGIA, NITROGÊNIO E FÓSFORO
}

\author{
Edwana Mara Moreira Monteiro1; Edilson Carvalho Brasil²; José de Brito Lourenço \\ Junior ${ }^{3}$; Cristiane do Socorro Barros ${ }^{4}$. \\ ${ }^{1}$ Universidade Federal Rural da Amazônia. Belém, Pará, Brasil. edmara6@yahoo.com.br \\ ${ }^{2}$ Embrapa Amazônia Oriental. Belém, Pará, Brasil. brasil@embrapa.br \\ ${ }^{3}$ Universidade Federal do Pará. Belém, Pará, Brasil. jblourenco@yahoo.com.br \\ ${ }^{4}$ Universidade Federal Rural da Amazônia. Belém, Pará, Brasil. cris_ufrazootec@yahoo.com.br
}

\begin{abstract}
RESUMO: O trabalho avaliou a produção de massa de forragem e composição químicobromatológica da gramínea Mombaça (Panicum maximum) adubada com resíduo orgânico da indústria siderúrgica (pó de balão) combinado com nitrogênio e fósforo, em condições de casa de vegetação. O delineamento experimental para produção de massa de forragem e composição químico-bromatológica foi blocos casualizados. Os fatores estudados foram: dois resíduos orgânicos, cama de aviário $\left(4 \mathrm{~g} \mathrm{dm}^{-3}\right)$ e pó de balão $\left(10 \mathrm{~g} \mathrm{dm}^{-3}\right)$, quatro níveis de $\mathrm{N}$ $\left(0,50,100,200 \mathrm{mg} \mathrm{dm}^{-3}\right)$ e quatro de $\mathrm{P}_{2} \mathrm{O}_{5}\left(0,100,200,300 \mathrm{mg} \mathrm{dm}^{-3}\right)$. A combinação dos resíduos orgânicos com dose de nitrogênio foi a que maior apresentou influência significativa nos teores de macrominerais $(\mathrm{N}, \mathrm{P}$ e K) e micronutriente $(\mathrm{Mn})$. A combinação dos resíduos orgânicos com dose de nitrogênio maior apresentou influência significativa nos teores de macrominerais $(\mathrm{N}, \mathrm{P}$ e $\mathrm{K})$ e micromineral $(\mathrm{Mn})$. O pó de balão proporcionou maiores teores de Fe e MO ao comparar com a cama de aviário. A aplicação de fósforo influenciou nas variáveis estudadas $\mathrm{Zn}, \mathrm{PB}$, FDA, lignina e celulose, sendo que, o maior teor obtido de cada variável esteve associado a $100 \mathrm{mg} \mathrm{kg}^{-1}$ de $\mathrm{P}$ para $\mathrm{Zn}$ e $300 \mathrm{mg} \mathrm{kg}^{-1}$ de $\mathrm{P}$ para as demais. $\mathrm{O}$ resíduo orgânico, pó de balão, torna-se contaminante do solo e da forragem devido à presença de metais pesados em sua composição, este fato pode ser limitante ao seu uso agrícola como adubo orgânico.
\end{abstract}

PALAVRAS-CHAVE: Adubação orgânica. Indústria siderúrgica. Macrominerais. Valor nutritivo.

\section{FORAGE MASS AND CHEMICAL-BROMATOLOGIC COMPOSITION OF THE MOMBAÇA (Panicum maximum) GRASS FERTILIZED WITH ORGANIC WASTE OF THE SIDERURGIC, NITROGEN AND PHOSPHORUS}

\begin{abstract}
This work evaluated the production of forage mass and chemicalbromatolologic composition of the Mombaça (Panicum maximum) grass fertilized with organic waste of the siderurgic industry (pó de balão) combinated with nitrogen and phosphorus, in conditions of greenhouse. For production of forage mass and chemicalbromatolologic, the complete randomized block design. The studied factors were: two organic wastes, poultry litter $\left(4 \mathrm{~g} \mathrm{dm}^{-3}\right)$ and "pó de balão" $\left(10 \mathrm{~g} \mathrm{dm}^{-3}\right)$, four levels of $\mathrm{N}(0,50,100$, $\left.200 \mathrm{mg} \mathrm{dm}^{-3}\right)$ and four of $\mathrm{P}_{2} \mathrm{O}_{5}\left(0,100,200,300 \mathrm{mg} \mathrm{dm}^{-3}\right)$. The combination of organic waste with the nitrogen significant influence in the contents of macroelements (N, P and K) and trace element (Mn). The "pó de balão" resulted in higher levels of Fe and OM when compared to the poultry-litter. The application of phosphorus influenced the variables $\mathrm{Zn}, \mathrm{CP}, \mathrm{ADF}$, lignin and cellulose, with the highest content obtained for each variable was associated with $100 \mathrm{mg} \mathrm{kg} 1 \mathrm{P}$ for $\mathrm{Zn}$ and $300 \mathrm{mg} \mathrm{kg1} \mathrm{P}$ for the others. The organic residue, "pó de balão", it
\end{abstract}


is contaminating the soil and forage due to the presence of heavy metals in its composition, this may be a limitation to its agricultural use as organic fertilizer.

KEYWORDS: Organic fertilization. Siderurgic industry. Macronutrients. Nutritional value.

\section{MASA DE FORRAJE Y COMPOSICIÓN QUÍMICA DE- BROMATOLÓGICA MOMBASA (Panicum maximum) FERTILIZADO CON RESIDUOS DE ACERO, NITRÓGENO Y FÓSFORO}

RESUMEN: El estudio evaluó la producción de masa de forraje y la composición química del pasto Mombasa (Panicum maximum) fertilizado con los residuos orgánicos de la industria siderúrgica (frasco de polvo), combinado con el nitrógeno y el fósforo en condiciones de invernadero. El diseño experimental para la producción de masa de forraje y la composición química fue de bloques al azar. Los factores estudiados fueron: dos residuos orgánicos, desechos de pollo $\left(4 \mathrm{~g} \mathrm{dm}^{-3}\right)$ y el frasco de polvo $\left(10 \mathrm{~g} \mathrm{dm}^{-3}\right)$, cuatro niveles de $\mathrm{N}(0,50,100$, $\left.200 \mathrm{mg} \mathrm{dm}^{-3}\right)$ y cuatro P2O5 (0, 100, 200, $\left.300 \mathrm{mg} \mathrm{dm}^{-3}\right)$. La combinación de los desechos orgánicos con dosis de nitrógeno que fue significativamente mayor influencia en los niveles de macro minerales (N, P y K) y micronutrientes (Mn). La combinación de residuos orgánicos con una mayor dosis de nitrógeno mostró una influencia significativa en los niveles de macro minerales (N, P y K) y de oligoelementos $(\mathrm{Mn})$. El frasco de polvo proporciona los niveles más altos de Fe y MO cuando se comparan con cama de pollo. La aplicación de P influyó en la variables de $\mathrm{Zn}, \mathrm{CP}, \mathrm{ADF}$, lignina y celulosa, con el contenido más alto obtenido para cada variable se asoció con $100 \mathrm{mg}$ de $\mathrm{P}$ kg-1 de $\mathrm{Zn}$ y $300 \mathrm{mg} \mathrm{P} \mathrm{kg}-1$ para demasiado. El residuo orgánico, frasco de polvo, se convierte en la contaminación del suelo y forraje debido a la presencia de metales pesados en su composición, este hecho puede ser limitante para su uso agrícola como fertilizante orgánico.

PALABRAS-CLAVE: Fertilizantes orgánicos. Industria del acero. Minerales macro. Valor nutricional.

\section{INTRODUÇÃO}

A importância dos sistemas de produção animal em pastejo pode ser constatada sob diferentes pontos de vista.

A pecuária bovina é importante por fornecer produtos de elevado valor biológico (carne e leite) para a alimentação humana, enquanto que, por um prisma social, ela pode contribuir para a fixação de trabalhadores no meio rural. Contudo, em face dos sistemas de produção existentes no país, fica claro a necessidade de maior atenção para com o manejo adequado da pastagem e para com a fertilidade do solo, visando assegurar a longevidade de pastagens mais produtivas (MARTHA JÚNIOR, 2003).

A fertilidade do solo tem origem na natureza química restritiva da maioria dos solos tropicais e no elevado potencial de extração de nutrientes do solo pelas plantas forrageiras (MACEDO, 2000). Os solos sob pastagem no Brasil geralmente 
apresentam teores de fósforo (P) muito baixos (CECATO et al., 2004). O P, além de sua importância na avaliação do valor nutritivo de uma forragem, é também um nutriente essencial para o crescimento das plantas e, portanto, limitante da produção máxima da cultura.

Para garantir o estabelecimento, a qualidade da forragem e a produtividade da pastagem, é necessário aplicação de fósforo. A adubação fosfatada estimula a absorção de nitrogênio (N) pela planta como conseqüência da correção da deficiência de $\mathrm{P}$ do solo e de aumento da eficiência no ciclo do N (SHUNKE, 2001).

Para se melhorar as produtividades das forrageiras, a correção de acidez do solo se faz necessário para diminuir a acidez potencial $(\mathrm{H}+\mathrm{Al})$ e, conseqüentemente, melhorar a disponibilidade de nutrientes e a atividade microbiana, o que reflete em favorecimento ao desenvolvimento do sistema radicular e da parte aérea das plantas (SANTANA et al., 2010).

No Brasil, a utilização de fertilizantes químicos para adubação de pastagens é muito utilizado, entretanto, a utilização de resíduos siderúrgicos para a mesma finalidade tem-se mostrado como uma alternativa viável, destacando-se o pó de balão com papel fundamental na adubação de pastagens por propiciar matéria orgânica ao solo (ALBUQUERQUE, 2008).
As diversas plantas forrageiras se comportam diferentemente quanto à acidez do solo. Algumas conseguem se estabelecer apresentando produções modestas em solos ácidos; outras, porém necessitam de solos com $\mathrm{pH}$ mais elevado para conseguir se estabelecer e apresentar boa produção.

A gramínea Panicum maximum cv. Mombaça é considerada uma das forrageiras tropicais mais produtivas à disposição dos pecuaristas. Em pastagens com uso racional de adubos e corretivos, a resposta dessa forrageira é bastante acentuada, porém, em situações de baixa fertilidade a produção é reduzida, caracterizando-se como uma forrageira exigente em fertilidade do solo (SILVA, 1995).

O presente trabalho teve por objetivo avaliar o efeito do resíduo orgânico, pó de balão combinado com doses de fósforo e nitrogênio sobre a massa de forragem e composição químico-bromatológica da gramínea Panicum maximum cv. Mombaça.

\section{MATERIAL E MÉTODOS}

Considerando-se que o resíduo possui baixíssimo teor de $\mathrm{N}$, em sua constituição, resultante do processo de geração, quando é submetido a elevadas temperaturas (acima de $1.000{ }^{\circ} \mathrm{C}$ ), no alto forno, a sua 
qualidade em termos de nutriente, geralmente, é inferior aos demais adubos orgânicos. Em decorrência disso, optou-se por realizar estudo em condições controladas, acrescentando-se tratamentos com adubação nitrogenada crescente, para avaliar a contribuição do nutriente, na melhoria da qualidade do resíduo, como adubo orgânico.

O trabalho foi conduzido em casa de vegetação, na Embrapa Amazônia Oriental, em Belém, Pará, localizada a $1^{\circ}$ $28^{\prime} \mathrm{S}$ e $48^{\circ} 27^{\prime} \mathrm{W}$, no período de novembro de 2009 a março de 2010.

Utilizou-se como substrato amostra da camada superficial $(0-20 \mathrm{~cm})$ de solo classificado como Latossolo Amarelo distrófico, textura média, coletada em área de floresta secundária, localizada na área da Embrapa Amazônia Oriental, em Belém, Pará.

A amostra de solo foi secada ao ar, destorroada e passada em peneira, com malha de $2 \mathrm{~mm}$ de abertura. Antes da instalação do experimento foram realizadas análises químicas e físicas nas amostras, no Laboratório de Solos da Embrapa Amazônia Oriental, em Belém, Pará, conforme metodologia descrita pela Embrapa (1997).

Os resultados das análises das amostras coletadas antes e após a instalação do experimento estão na Tabela 1.

Tabela 1 - Características químicas e físicas do Latossolo Amarelo distrófico, textura média, coletado na camada de 0 a 20 cm, em Belém, Pará.

\begin{tabular}{|c|c|}
\hline Característica química $^{1}$ & Valor \\
\hline $\mathrm{pH}$ em $\mathrm{H}_{2} \mathrm{O}$ & 4,5 \\
\hline $\mathrm{N}(\%)$ & 0,13 \\
\hline $\mathrm{P}\left(\mathrm{mg} \mathrm{dm}^{-3}\right) \mathrm{P}-$ Melhlich - 1 & 2 \\
\hline $\mathrm{K}\left(\mathrm{mg} \mathrm{dm}^{-3}\right) \mathrm{K}-$ Melhlich - 1 & 15 \\
\hline $\mathrm{Na}\left(\mathrm{mg} \mathrm{dm}^{-3}\right)$ & 9 \\
\hline $\mathrm{Ca}\left(\mathrm{cmol}_{\mathrm{c}} \mathrm{dm}^{-3}\right)$ & 0,3 \\
\hline $\mathrm{Mg}\left(\mathrm{cmol}_{\mathrm{c}} \mathrm{dm}^{-3}\right)$ & 0,2 \\
\hline $\mathrm{Al}\left(\mathrm{cmol}_{\mathrm{c}} \mathrm{dm}^{-3}\right)$ & 1,6 \\
\hline $\mathrm{H}+\mathrm{Al}\left(\mathrm{cmol}_{\mathrm{c}} \mathrm{dm}^{-3}\right)$ & 5,7 \\
\hline M.O $\left(\mathrm{g} \mathrm{kg}^{-1}\right)$ & 9,9 \\
\hline CTC pH 7,0 $\left(\mathrm{cmol}_{\mathrm{c}} \mathrm{dm}^{-3}\right)$ & 6,21 \\
\hline Saturação por bases (\%) & 8,13 \\
\hline Característica física $^{1}$ & Valor \\
\hline Argila $\left(\mathrm{g} \mathrm{kg}^{-1}\right)$ & 160 \\
\hline Silte $\left(\mathrm{g} \mathrm{kg}^{-1}\right)$ & 64 \\
\hline Areia $\left(\mathrm{g} \mathrm{kg}^{-1}\right)$ & 796 \\
\hline
\end{tabular}

${ }^{1}$ Média de duas repetições.

$\mathrm{O}$ pH em água foi determinado em suspensão na proporção solo-líquido 1:2,5.
$\mathrm{O} \mathrm{Ca}, \mathrm{Mg}$ e $\mathrm{Al}$ foram extraídos utilizandose solução de $\mathrm{KCl} 1 \mathrm{~N}$, enquanto o $\mathrm{P}, \mathrm{K}$ e 
Na com solução de Mehlich I e o $\mathrm{H}+\mathrm{Al}$, com acetato de $\mathrm{Ca} 1 \mathrm{~N}, \mathrm{pH}$ 7,0. A análise granulométrica envolveu a determinação de areia, silte e argila.

Para correção da acidez do solo utilizou-se calcário dolomítico, com PRNT de $100 \%$. As quantidades de calcário foram calculadas pelo critério de saturação por bases, para $60 \%$, utilizando-se a seguinte fórmula: NC (t/ha) = (V2 - V1).CTC/100, onde $\mathrm{NC}=$ necessidade de calagem; $\mathrm{V} 2$ = percentagem de saturação por base desejada; V1 = percentagem de saturação por base inicial do solo.

Após a aplicação do corretivo, na quantidade de $10 \mathrm{~g} / \mathrm{vaso}$, o solo ficou em incubação por 30 dias, em vasos com capacidade de cinco $\mathrm{dm}^{3}$ de terra, mantendo-se a umidade próxima à capacidade máxima de retenção de água.

Após a incubação, as amostras receberam aplicação dos tratamentos, com resíduos orgânicos (pó de balão e cama de aviário) e minerais ( $\mathrm{P}$ e $\mathrm{N}$ ), conjuntamente com adubação básica de $100 \mathrm{mg} \mathrm{dm}^{-3} \mathrm{de} \mathrm{K}$, na forma de cloreto de potássio $(\mathrm{KCl}) ; 5$ $\mathrm{mg} \mathrm{dm}^{-3}$ de $\mathrm{Zn}$, na forma de sulfato de zinco $\left(\mathrm{ZnSO}_{4} .7 \mathrm{H}_{2} \mathrm{O}\right) ; 0,5 \mathrm{mg} \mathrm{dm}^{-3} \mathrm{de} \mathrm{B}$, na forma de ácido bórico $\left(\mathrm{H}_{3} \mathrm{BO}_{3}\right) ; 1,0 \mathrm{mg}$ $\mathrm{dm}^{-3} \mathrm{de} \mathrm{Cu}$, na forma de sulfato de cobre pentahidratado $\left(\mathrm{CuSO}_{4} .5 \mathrm{H}_{2} \mathrm{O}\right)$.

Os nutrientes foram aplicados, na forma de solução, com $20 \mathrm{ml} / \mathrm{vaso}$, por ocasião do corte de uniformização da forrageira (Panicum maximum cv. Mombaça), exceto o nitrogênio, em que a aplicação foi dividida em três parcelas, a primeira, na ocasião do corte de uniformização, e outras duas, a cada 10 dias.

$\mathrm{Na}$ Tabela 2 estão os resultados das análises químicas dos dois resíduos orgânicos estudados, realizadas no Laboratório Campo Análises Agrícolas e Ambientais, em Paracatu, Minas Gerais.

Para produção de massa de forragem, análise de nutrientes e composição bromatológica, o delineamento experimental foi em blocos casualizados, em esquema fatorial $2 \times 4 \times 4$, com 32 tratamentos e duas repetições. Os fatores estudados foram: dois resíduos orgânicos, cama de aviário, na dose de $4 \mathrm{~g} \mathrm{dm}^{-3}$ e pó de balão, $10 \mathrm{~g} \mathrm{dm}^{-3}$, quatro níveis de $\mathrm{N}(0$, 50, 100, $200 \mathrm{mg} \mathrm{dm}^{-3}$ ), na forma de ureia, e quatro de $\mathrm{P}_{2} \mathrm{O}_{5}, 0,100,200,300 \mathrm{mg} \mathrm{dm}^{-3}$, como fosfato natural reativo de Arad.

As sementes de Panicum maximum cv. Mombaça possuíam as seguintes características: Pureza $=90,5 \%$; Germinação $=81 \% ; \mathrm{VC}=73,3 \%$. As sementes foram germinadas em bandejas de plástico, utilizando-se areia lavada, como substrato. Após 20 dias da germinação, foram transplantadas cinco plantas, por vaso, com altura média de 10 centímetros. 
A irrigação foi efetuada para manter a umidade do solo, em $70 \%$ da capacidade de embebimento do solo, fazendo-se regas diárias, durante o período de execução do experimento.

Após 15 dias do transplantio realizouse corte de uniformização das plantas, a 15 cm do solo. Para avaliação do experimento realizaram-se dois cortes na sua parte aérea, o primeiro, aos 30 dias do corte de uniformização, e o segundo, aos 60 dias.

Tabela 2 - Análise química (\%) dos resíduos orgânicos utilizados.

\begin{tabular}{lcc}
\hline \multirow{2}{*}{ Característica $(\%)$} & \multicolumn{2}{c}{ Resíduo orgânico } \\
\cline { 2 - 3 } Umidade a $65^{\circ} \mathrm{C}$ & Cama de aviário & Pó de balão \\
Carbono orgânico & 0,5 & 22,1 \\
$\mathrm{P}_{2} \mathrm{O}_{5}$ - total & 2,8 & 0,12 \\
$\mathrm{~K}_{2} \mathrm{O}$ & 0,17 & 0,17 \\
$\mathrm{CaO}$ & 0,38 & 2,01 \\
$\mathrm{MgO}$ & 4,16 & 0,50 \\
$\mathrm{~S}$ & 0,54 & 0,10 \\
$\mathrm{~B}$ & 0,08 & 0,001 \\
$\mathrm{Zn}$ & 0,004 & 0,030 \\
$\mathrm{Fe}$ & 0,001 & 11,87 \\
$\mathrm{Mn}$ & 1,28 & 0,25 \\
$\mathrm{Cu}$ & 0,02 & 0,004 \\
$\mathrm{Co}$ & 0,002 & $<0,001$ \\
$\mathrm{Mo}$ & - & $<0,001$ \\
$\mathrm{Cl}$ & - & $<0,07$ \\
$\mathrm{Si}$ total & - & 2,07 \\
$\mathrm{Cr}$ & - & 0,02 \\
$\mathrm{Cd}$ & 0,011803 & 0,0004 \\
$\mathrm{~Pb}$ & $<0,0000288$ & $<0,0005$ \\
$\mathrm{As}$ & $<0,00446$ & 0,0002 \\
$\mathrm{Hg}$ & 0,000126 & 0,000009 \\
$\mathrm{Se}$ & 0,0000001 & 0,000024 \\
$\mathrm{~V}$ & 0,00021 & 0,002207 \\
$\mathrm{Ba}$ & 0,03352 & 0,013885 \\
$\mathrm{~N}$ total & 0,04311 & 0,005 \\
$\mathrm{pH}$ em CaCl & $<0,06$ & 8,0 \\
$\mathrm{Lab}$ & 8,9 &
\end{tabular}

Laboratório Campo Análises Agrícolas e Ambientais - PARACATU/MG.

As análises laboratoriais de composição bromatológica foram realizadas, em Belém, Pará, no Laboratório de Análise de Alimentos do Departamento de Zootecnia, da Universidade Federal Rural da Amazônia. As amostras foram secadas em estufa de ventilação forçada de ar, com temperatura de $65^{\circ} \mathrm{C}$, por 72 horas, para determinação da matéria seca, de acordo com Silva e Queiroz (2002). Depois de moídas, em moinho tipo Willey, com peneira de $1 \mathrm{~mm}$, foram levadas à 
estufa, a $105{ }^{\circ} \mathrm{C}$, por 24 horas, para obtenção do percentual de MS da amostra seca na estufa (ASE). O percentual de MS final correspondeu ao resíduo da ASA e ASE, dividido por 100.

Amostras de ASA foram analisadas nos seus conteúdos de proteína bruta (PB), pelo método semimicro Kjeldahl (AOAC, 1997). Os teores de matéria orgânica (MO) foram calculados subtraindo-se da MS, o percentual de matéria mineral (MM), obtido pela incineração das amostras, em mufla, a $550{ }^{\circ} \mathrm{C}$, por cinco horas. Os teores de fibra em detergente neutro (FDN), fibra em detergente ácido (FDA) e lignina (LIG) foram determinados pelo método descrito por Van Soest (1994), enquanto que os de celulose (CEL) e hemicelulose (HEM), pela metodologia de Silva e Queiroz (2002).

As determinações de macro e microminerais no tecido vegetal foram realizadas conforme metodologia descrita por Sarruge e Haag (1974), coletando-se amostras na parte aérea, durante todo o período experimental, no Laboratório de Análise de Solos da Embrapa Amazônia Oriental, em Belém, Pará. Determinaramse os teores dos macrominerais $(\mathrm{N}, \mathrm{P}, \mathrm{K}$, $\mathrm{Ca}$ e $\mathrm{Mg})$ e microminerais $(\mathrm{Cu}, \mathrm{Mn}, \mathrm{Fe}$ e $\mathrm{Zn})$. O $\mathrm{N}$ total foi obtido de acordo com o método de Kjeldhal. Os nutrientes P, K, Ca e $\mathrm{Mg}$ foram determinados após a digestão com solução nitro-perclórica 2:1. O P foi quantificado por colorimetria, $\mathrm{K}$ por fotometria de chama e $\mathrm{Ca}, \mathrm{Mg}$ e microminerais, por espectrofotometria de absorção atômica.

Os resultados das variáveis estudadas foram submetidos à análise de variância, para avaliar o efeito dos resíduos orgânicos, níveis de $\mathrm{P}_{2} \mathrm{O}_{5}$ e níveis de $\mathrm{N}$. Os efeitos do nitrogênio e $\mathrm{P}_{2} \mathrm{O}_{5}$ foram avaliados por análise de regressão, através da decomposição da soma de quadrado de $\mathrm{P}_{2} \mathrm{O}_{5}$ e $\mathrm{N}$, em efeitos linear, quadrático e cúbico. Os resíduos orgânicos foram comparados pelo teste Tukey (teste F), em nível de $5 \%$ de probabilidade.

\section{RESULTADOS E DISCUSSÃO}

A aplicação de calcário promoveu aumento significativo do $\mathrm{pH}$ do solo de 4,5 atingindo valores próximos a 6,0, o que indica que houve redução significativa da acidez. Esse efeito é bem conhecido, em decorrência da dissolução do carbonato de cálcio e magnésio no solo, que resulta em liberação de hidroxila e bicarbonato, que atuam como elementos neutralizantes da acidez do solo (RAIJ, 1991). A aplicação dos resíduos orgânicos, combinada com $\mathrm{P}$ e N, promoveu elevação nos teores de Ca e $\mathrm{Mg}$ no solo. Observou-se que as concentrações de $\mathrm{Ca}$ e $\mathrm{Mg}$ passaram de 0,3 e $0,2 \mathrm{cmol}_{\mathrm{c}} \mathrm{dm}^{-3}$, respectivamente, para valores próximos a 2,8 e 5,0 $\mathrm{cmol}_{\mathrm{c}} \mathrm{dm}^{-3}$ 
(Tabela 3). A aplicação de resíduos orgânicos, além de diminuir a acidez do solo, aumenta a concentração de $\mathrm{Ca}$ e $\mathrm{Mg}$, em função da solubilização do resíduo e liberação desses nutrientes no solo (CIOTTA, 2004).

Tabela 3 - Atributos químicos do Latossolo Amarelo distrófico, textura média, após a aplicação de calcário, resíduos orgânicos, $\mathrm{P}_{2} \mathrm{O}_{5}$ e nitrogênio, em Belém, PA.

\begin{tabular}{|c|c|c|c|c|c|c|c|c|c|c|}
\hline \multirow{5}{*}{$\begin{array}{c}\text { Combinação } \\
\mathrm{P}_{2} \mathrm{O}_{5} \text { e N } \\
\left(\mathrm{mg} \mathrm{dm}^{-3}\right)\end{array}$} & $\mathrm{pH}$ & $\mathrm{N}$ & $\mathrm{MO}$ & $\mathrm{P}$ & $\mathrm{K}$ & $\mathrm{Na}$ & $\mathrm{Ca}$ & $\mathrm{Ca}+\mathrm{Mg}$ & $\mathrm{Al}$ & $\mathrm{H}+\mathrm{Al}$ \\
\hline & água & $\%$ & $\mathrm{~g} \mathrm{~kg}^{-1}$ & \multicolumn{3}{|c|}{$\mathrm{mg} \mathrm{dm}^{-3}$} & \multicolumn{4}{|c|}{$\mathrm{cmol}_{\mathrm{c}} \mathrm{dm}^{-3}$} \\
\hline & \multicolumn{10}{|c|}{ Antes da aplicação dos tratamentos } \\
\hline & 4,5 & 0,13 & 9,9 & 2 & 15 & 9 & 0,3 & 0,5 & 1,6 & 5,7 \\
\hline & \multicolumn{10}{|c|}{ Cama de aviário $\left(4 \mathrm{mg} \mathrm{dm}^{-3}\right)$} \\
\hline N0 P0 & 5,9 & 0,14 & 10,8 & 10,0 & 67,0 & 42,5 & 2,2 & 4,0 & 0,1 & 2,1 \\
\hline N50 P0 & 5,9 & 0,14 & 10,4 & 10,5 & 79,5 & 36,5 & 2,1 & 3,7 & 0,1 & 2,2 \\
\hline N100 P0 & 5,8 & 0,16 & 15,3 & 17,0 & 86,5 & 38,5 & 2,2 & 4,1 & 0,1 & 2,0 \\
\hline N200 P0 & 5,9 & 0,16 & 12,2 & 18,0 & 95,0 & 32,5 & 2,2 & 3,9 & 0,1 & 1,7 \\
\hline N0 P100 & 5,8 & 0,14 & 11,7 & 79,5 & 70,5 & 35,5 & 2,2 & 3,8 & 0,1 & 2,1 \\
\hline N50 P100 & 5,7 & 0,14 & 13,5 & 82,0 & 81,5 & 53,5 & 2,1 & 3,8 & 0,1 & 2,1 \\
\hline N100 P100 & 5,7 & 0,14 & 13,1 & 83,5 & 103,0 & 48,0 & 2,3 & 4,2 & 0,1 & 2,2 \\
\hline N200 P100 & 5,9 & 0,16 & 12,1 & 92,5 & 114,5 & 43,0 & 2,2 & 4,1 & 0,1 & 1,8 \\
\hline N0 P200 & 5,6 & 0,15 & 13,9 & 104,5 & 72,0 & 41,0 & 2,1 & 3,7 & 0,1 & 2,0 \\
\hline N50 P200 & 5,6 & 0,15 & 14,9 & 132,0 & 85,5 & 43,0 & 2,3 & 4,3 & 0,1 & 2,2 \\
\hline N100 P200 & 5,8 & 0,16 & 15,9 & 135,5 & 95,0 & 47,0 & 2,2 & 4,2 & 0,1 & 2,3 \\
\hline N200 P200 & 5,9 & 0,17 & 16,6 & 150,0 & 147,0 & 44,0 & 2,2 & 3,9 & 0,1 & 1,7 \\
\hline N0 P300 & 5,7 & 0,14 & 11,7 & 179,5 & 88,5 & 54,0 & 2,4 & 4,1 & 0,1 & 2,3 \\
\hline N50 P300 & 5,6 & 0,14 & 12,9 & 225,5 & 90,0 & 47,0 & 2,2 & 3,8 & 0,1 & 2,5 \\
\hline N100 P300 & 5,8 & 0,15 & 13,3 & 264,5 & 103,0 & 50,0 & 2,4 & 4,3 & 0,1 & 2,6 \\
\hline \multirow[t]{2}{*}{ N200 P300 } & 5,9 & 0,15 & 14,9 & 268,5 & 104,5 & 51,0 & 2,2 & 4,0 & 0,1 & 1,9 \\
\hline & \multicolumn{10}{|c|}{ Pó de balão $\left(10 \mathrm{mg} \mathrm{dm}^{-3}\right)$} \\
\hline N0 P0 & 5,7 & 0,13 & 10,1 & 4,0 & 56,0 & 25,0 & 2,3 & 3,8 & 0,1 & 1,7 \\
\hline N50 P0 & 5,8 & 0,13 & 11,1 & 6,0 & 48,0 & 23,0 & 2,3 & 3,8 & 0,1 & 1,5 \\
\hline N100 P0 & 5,8 & 0,14 & 10,6 & 6,0 & 56,0 & 25,0 & 2,6 & 4,0 & 0,1 & 2,5 \\
\hline N200 P0 & 5,9 & 0,15 & 10,4 & 15,0 & 52,0 & 23,0 & 2,6 & 4,6 & 0,1 & 1,2 \\
\hline N0 P100 & 5,6 & 0,13 & 10,5 & 54,0 & 56,0 & 25,0 & 2,6 & 4,4 & 0,1 & 1,8 \\
\hline N50 P100 & 5,8 & 0,13 & 11,4 & 63,0 & 62,0 & 31,0 & 2,6 & 4,3 & 0,1 & 1,8 \\
\hline N100 P100 & 5,8 & 0,14 & 11,9 & 84,0 & 43,0 & 29,0 & 2,4 & 4,2 & 0,1 & 1,5 \\
\hline N200 P100 & 5,8 & 0,14 & 10,5 & 96,0 & 52,0 & 29,0 & 2,5 & 4,0 & 0,1 & 1,5 \\
\hline N0 P200 & 5,7 & 0,13 & 10,7 & 97,0 & 68,0 & 37,0 & 2,5 & 4,0 & 0,1 & 2,0 \\
\hline N50 P200 & 5,8 & 0,13 & 10,5 & 105,0 & 52,0 & 27,0 & 2,5 & 4,7 & 0,1 & 1,7 \\
\hline N100 P200 & 5,8 & 0,14 & 10,8 & 158,0 & 56,0 & 29,0 & 2,7 & 4,7 & 0,1 & 1,5 \\
\hline N200 P200 & 5,9 & 0,14 & 10,7 & 181,0 & 62,0 & 31,0 & 2,5 & 4,5 & 0,1 & 1,7 \\
\hline N0 P300 & 5,4 & 0,13 & 11,1 & 234,0 & 52,0 & 31,0 & 2,5 & 4,3 & 0,1 & 1,7 \\
\hline N50 P300 & 5,6 & 0,13 & 11,9 & 248,0 & 54,0 & 33,0 & 2,5 & 4,3 & 0,1 & 2,2 \\
\hline N100 P300 & 5,6 & 0,14 & 11,2 & 257,0 & 56,0 & 33,0 & 2,7 & 4,7 & 0,1 & 1,7 \\
\hline N200 P300 & 5,7 & 0,15 & 11,6 & 334,0 & 66,0 & 38,0 & 2,8 & 5,0 & 0,1 & 1,7 \\
\hline
\end{tabular}

A aplicação de doses crescentes de $\mathrm{P}_{2} \mathrm{O}_{5}$ promoveu aumento no teor de fósforo no solo, de 2,0 $\mathrm{mg} \mathrm{dm}^{-3}$, para valores próximos a $350 \mathrm{mg} \mathrm{dm}^{-3}$, nos tratamentos que receberam as maiores doses do nutriente. Aumentos nos teores de fósforo disponíveis no solo, em função da aplicação de doses crescentes de 
fertilizantes fosfatados, foram, também, observados por (RIBEIRO et al., 2009).

Observou-se redução considerável no teor de alumínio trocável, em função dos resíduos orgânicos utilizados, independentemente da quantidade de $\mathrm{P}_{2} \mathrm{O}_{5}$ aplicado.

Constatou-se redução da concentração inicial de $\mathrm{Al}$, da ordem de 1,6 $\mathrm{cmol}_{\mathrm{c}} \mathrm{dm}^{-3}$, para $0,1 \mathrm{cmol}_{\mathrm{c}} \mathrm{dm}^{-3}$, que indica efeito positivo da aplicação do calcário na neutralização do alumínio trocável do solo. Pesquisas realizadas com aplicação de calcário na superfície, em solos brasileiros, indicam aumentos de $\mathrm{pH}$ e dos teores de $\mathrm{Ca}$ e $\mathrm{Mg}$ trocáveis, e redução do $\mathrm{Al}$ trocável, até camadas de 20-40 cm (CAIRES et al., 2001). Esse efeito decorre da atuação dos carbonatos de $\mathrm{Ca}$ e $\mathrm{Mg}$ no solo, quando os receptores de prótons (hidroxila e bicarbonato) reagem no solo, e neutralizam, gradualmente, a acidez total, inclusive o alumínio trocável (RAIJ, 1991).

A produção de massa de forragem da parte aérea da gramínea Mombaça foi influenciada significativamente $(\mathrm{p}<0,05)$ pelas doses dos resíduos orgânicos utilizados e doses de $\mathrm{N}$, sem diferenças significativas em relação às doses de $\mathrm{P}_{2} \mathrm{O}_{5}$ e interações.

A cama de aviário $\left(22,81 \mathrm{~g} \mathrm{vaso}^{-1}\right)$ proporcionou maior produção de massa de forragem, em comparação ao pó de balão $\left(16,50 \mathrm{~g} \mathrm{vaso}^{-1}\right)$. Os dados obtidos pelo presente estudo são similares aos de Lavres Júnior (2001), entre 14,56 e 27,85 $\mathrm{g} \mathrm{vaso}^{-1}$. Independente dos resíduos orgânicos utilizados e doses de $\mathrm{P}_{2} \mathrm{O}_{5}$, a massa de forragem da gramínea apresentou aumento linear, em resposta à aplicação de doses crescentes de nitrogênio (Gráfico 1).

Gráfico 1 - Massa de forragem $\left(\mathrm{g} \mathrm{vaso}^{-1}\right.$ ) de Panicum maximum cv. Mombaça, em função das doses de nitrogênio, em Belém, Pará.

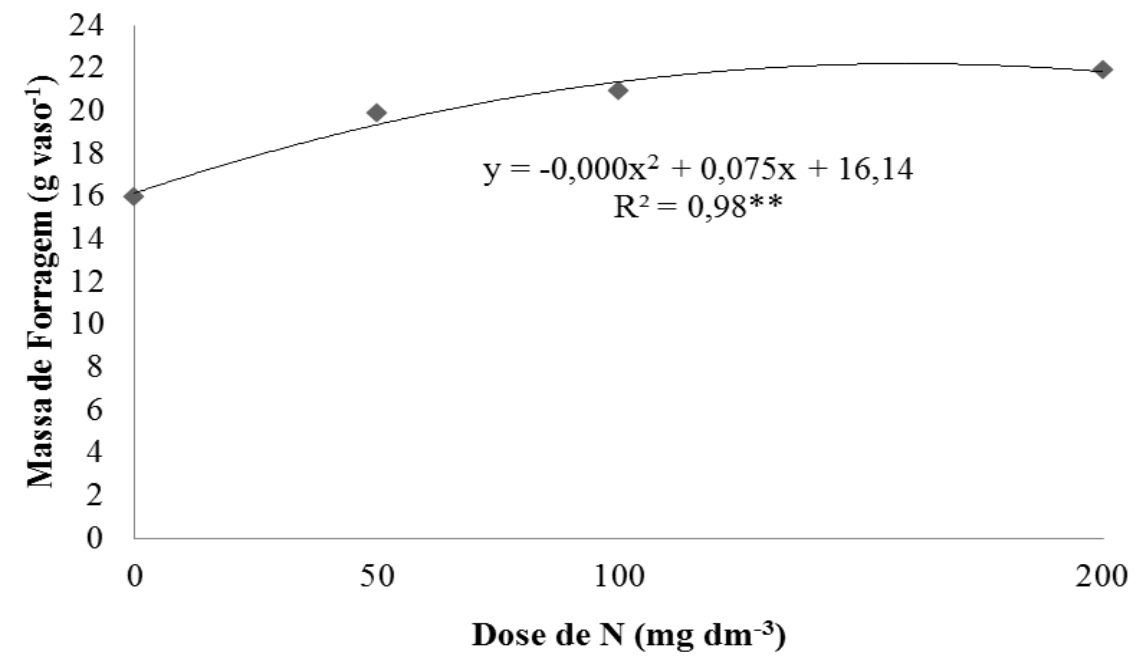


Observou-se que, com aumento quadrático na massa de forragem com o aumento das doses de $\mathrm{N}$, houve maior produção de massa de forragem da gramínea, similar ao encontrado por (MELLO et al., 2008). Assim, a adubação nitrogenada, por disponibilizar $\mathrm{N}$ ao sistema solo-planta, torna-se fator dominante que controla os diferentes processos de crescimento e desenvolvimento da planta.

$\mathrm{O} \mathrm{N}$ se manifesta, de um lado, por melhorar, diretamente, a eficiência da fotossíntese e, por outro, promover a redistribuição prioritária do carbono para a formação da parte aérea (SANTOS et al., 2008). Costa (1995), na produção do capim-elefante, fertilizado com doses de nitrogênio de 0,50 e $100 \mathrm{mg} \mathrm{dm}^{-3}$, obteve produção de massa de forragem de 20,62; 25,49 e 29,62 $\mathrm{g} \mathrm{vaso}^{-1}$, enquanto Andrade et al. (2000), ao avaliaram sete doses de nitrogênio, 20, 50, 100, 200, 300, 350 e $380 \mathrm{mg} \mathrm{dm}^{-3}$, observaram efeito significativo do $\mathrm{N}$ sobre a produção de massa de forragem, de 25,49 a 47,31 g vaso $^{-1}$, e ocasionou aumento de $85,6 \%$ na produtividade.

A interação do resíduo orgânico vs. dose de $\mathrm{N}$ influenciou positivamente $(\mathrm{p}<0,05)$ no teor de $\mathrm{N}$ da gramínea Mombaça (Gráfico 2).
De maneira geral, ocorreu elevação linear no teor médio de $\mathrm{N}$ da matéria seca da parte aérea da gramínea, com aumento das doses de $\mathrm{N}$, combinadas com resíduos orgânicos. Entretanto, o teor de N (16,94 g $\mathrm{kg}^{-1}$ ) foi obtido nas diferentes combinações dos resíduos orgânicos, com a dose de $\mathrm{N}$ $\left(50 \mathrm{mg} \mathrm{dm}^{-3}\right)$. Isso se explica pelo fato da adubação nitrogenada acelerar o crescimento, perfilhamento, produção de folha e, consequentemente, expansão da parte aérea (FREITAS et al., 2005). Os dados obtidos pelo presente estudo são similares aos de Lavres Júnior (2001), de 14,56 a 27,85 $\mathrm{g} \mathrm{kg}^{-1}$, e aos de Manarin e Monteiro (2002), que constataram variação nos teores de $\mathrm{N}$ de Mombaça, de 8,8 a 18,5 $\mathrm{g} \mathrm{kg}^{-1}$, em folhas recém-expandidas.

$O$ teor de fósforo da gramínea Mombaça apresentou efeito significativo negativo $(p<0,05)$ na interação resíduo orgânico vs. dose de nitrogênio (Gráfico $3)$.

Com aumento das doses de N, combinadas com ambos os resíduos orgânicos, diminuiu o teor de $\mathrm{P}$ da parte aérea da gramínea, o que pode ter ocorrido pela diluição do nutriente na planta, decorrente do aumento de produção de massa seca da parte aérea, com aumento das doses de nitrogênio fornecidas na solução nutritiva. Esse fato já foi demonstrado para Panicum maximum, nos 
capins Aruana, Mombaça e Tanzânia MONTEIRO, 2010).

(SANTOS JÚNIOR, 2005; SILVEIRA;

Gráfico 2 - Teor médio de $\mathrm{N}\left(\mathrm{g} \mathrm{kg}^{-1}\right)$ na matéria seca de Panicum maximum cv. Mombaça, em função da interação, resíduo orgânico vs. dose de nitrogênio, em Belém, Pará. CA: Cama de aviário, PDB: Pó de balão.

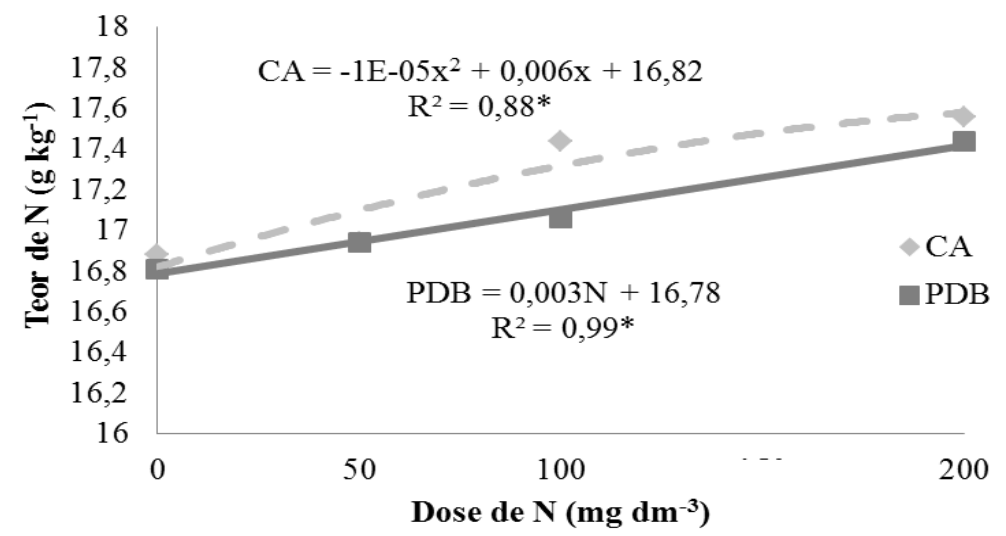

Gráfico 3 - Teor médio de $\mathrm{P}\left(\mathrm{g} \mathrm{kg}^{-1}\right)$ na matéria seca de Panicum maximum cv. Mombaça, em função da interação, resíduo orgânico vs. dose de nitrogênio, em Belém, Pará. CA: Cama de aviário, PDB: Pó de balão.

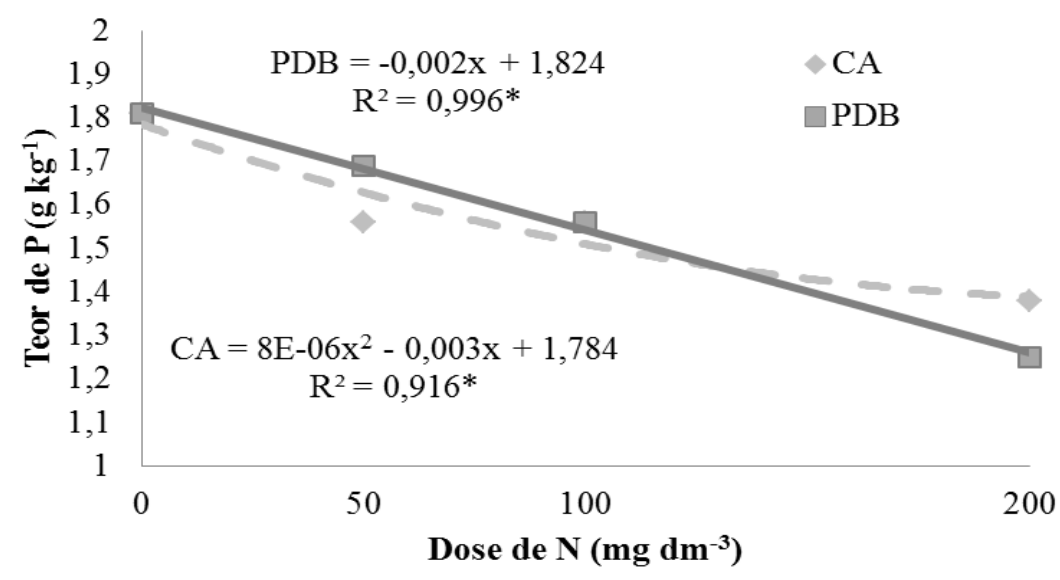

$\mathrm{O}$ teor de $\mathrm{K}$ apresentou efeito significativo positivo $(\mathrm{p}<0,05)$ da interação resíduo orgânico vs. dose de nitrogênio (Gráfico 4).

O teor máximo de $\mathrm{K}\left(16,19 \mathrm{~g} \mathrm{~kg}^{-1}\right)$ foi obtido com a combinação do resíduo orgânico PDB e dose de $\mathrm{N}\left(200 \mathrm{mg} \mathrm{dm}^{-3}\right)$. Os teores de $\mathrm{K}$ da parte aérea com pó de balão estão dentro do recomendado por Malavolta, Vitti e Oliveira (1997), 14,3 a $18,4 \mathrm{~g} \mathrm{~kg}^{-1}$. Resultados contrários foram relatados por (COSTA et al., 2003), que 
afirmaram que a adubação nitrogenada não exerceu influência sobre os teores de $\mathrm{K}$. Prevê-se que os teores médios de $\mathrm{K}$, nas diferentes doses de $\mathrm{N}$, combinadas com pó de balão, estariam a suprir as necessidades de bovinos de corte e de leite segundo o
NRC (2000, 2001), 6 e 10 g kg-1, respectivamente, bem como ovinos e caprinos, de 5 a $8 \mathrm{~g} \mathrm{~kg}^{-1}$ (NRC, 1985), é de situação que também ocorreu ao adubar a gramínea Mombaça com cama de aviário, que variou de 11,94 a 14,06 g kg-1

Gráfico 4 - Teor médio de $\mathrm{K}\left(\mathrm{g} \mathrm{kg}^{-1}\right)$ na matéria seca de Panicum maximum cv. Mombaça, em função da interação, resíduo orgânico vs. dose de nitrogênio, em Belém, Pará. CA: Cama de aviário, PDB: Pó de balão.

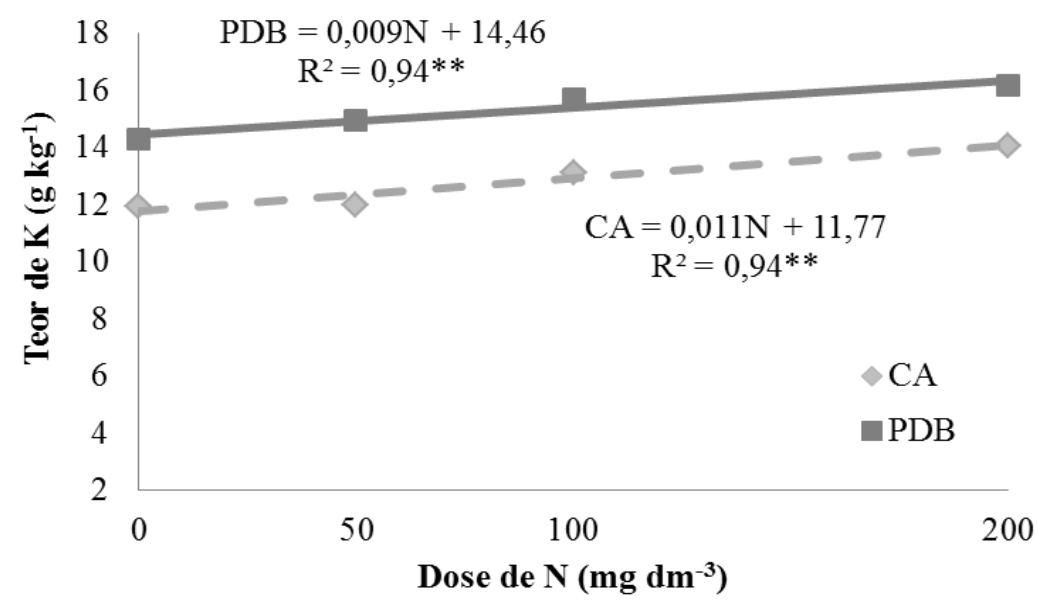

Os teores de $\mathrm{Ca}$ e $\mathrm{Mg}$ não apresentaram efeito significativo $(\mathrm{p}>0,05)$, com relação às fontes de variação analisadas. No teor de cobre houve efeito somente da interação dose de $\mathrm{N}$ vs. dose de $\mathrm{P}_{2} \mathrm{O}_{5}$ (Gráfico 5). Verifica-se aumento linear em todas as combinações de doses de $\mathrm{N}$ e de $\mathrm{P}_{2} \mathrm{O}_{5}$, entretanto, a combinação da doses de $\mathrm{N}(0 \mathrm{mg}$ dm 3$)$ e de $\mathrm{P}_{2} \mathrm{O}_{5}(300$ $\mathrm{mg} \mathrm{dm}^{-3}$ ) proporcionou maior teor de $\mathrm{Cu}$ (5,73 $\left.\mathrm{mg} \mathrm{kg}^{-1}\right)$, na gramínea. Os resultados de $\mathrm{Cu}$ obtidos no presente trabalho são inferiores aos de (COSTA et al., 2003), em Tanzânia, com teores de $\mathrm{Cu}$, na faixa de
6,9 a $9,3 \mathrm{mg} \mathrm{kg}^{-1}$. Os teores de $\mathrm{Cu}$ obtidos são insuficientes para atender as exigências de bovinos de leite e de corte, que é de 16 mg kg-1 e $10 \mathrm{mg} \mathrm{kg}^{-1}$ (NRC 2001, 2000), respectivamente, entretanto, próximos aos valores ideais, de $10 \mathrm{mg} \mathrm{kg}^{-1}$, adequados para as exigências de ovinos (FREITAS et al., 2007).

$\mathrm{O}$ teor de $\mathrm{Mn}$ apresentou efeito significativo $(p<0,05)$, na interação resíduo orgânico vs. dose de N (Gráfico 6). Com aumento nas doses de $\mathrm{N}$ combinadas com cama de aviário, ocorreu elevação quadrática no teor de $\mathrm{Mn}$, entretanto, ao 
combinar com o resíduo orgânico pó de balão, houve aumento linear. A elevação no teor de Mn está ligada não somente à utilização da adubação nitrogenada, mas, também, pela neutralização do $\mathrm{pH}$ do solo, que facilita a disponibilidade de Mn.
Segundo o NRC (2000), os requerimentos em Mn para gado de corte e leiteiro apresentam variação de 20 a $40 \mathrm{mg} \mathrm{kg}^{-1}$. Dessa forma, os teores determinados neste trabalho são superiores às exigências de ambas as categorias.

Gráfico 5 - Teor médio de $\mathrm{Cu}\left(\mathrm{mg} \mathrm{kg}^{-1}\right)$ na matéria seca de Panicum maximum cv. Mombaça, em função da interação, dose de nitrogênio vs. dose de $\mathrm{P}_{2} \mathrm{O}_{5}$, em Belém, Pará.

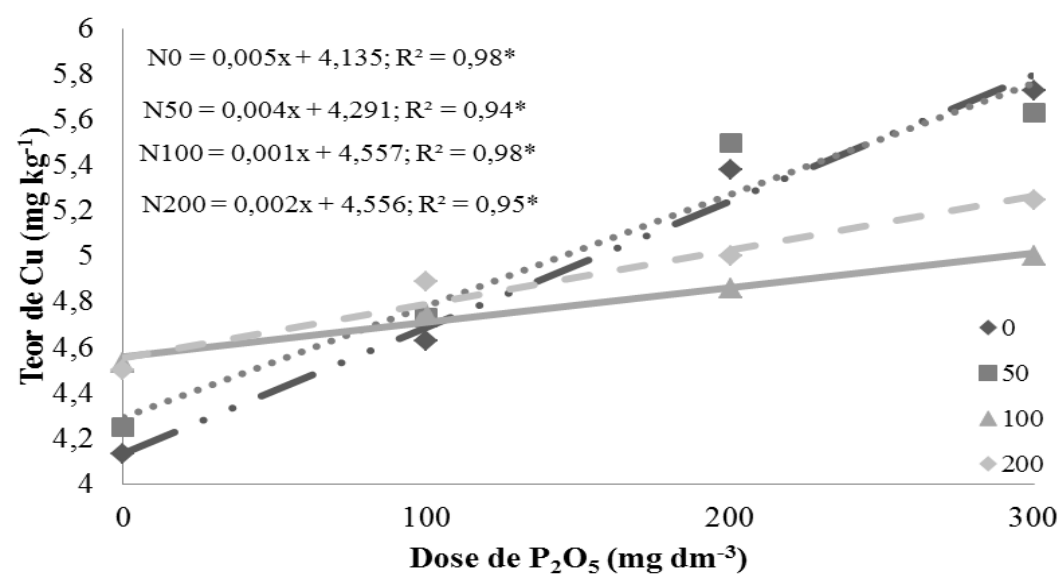

Gráfico 6 - Teor médio de Mn ( $\left.\mathrm{mg} \mathrm{kg}^{-1}\right)$ na matéria seca de Panicum maximum cv. Mombaça, em função da interação, resíduo orgânico vs. dose de nitrogênio, em Belém, Pará. CA: Cama de aviário, PDB: Pó de balão.

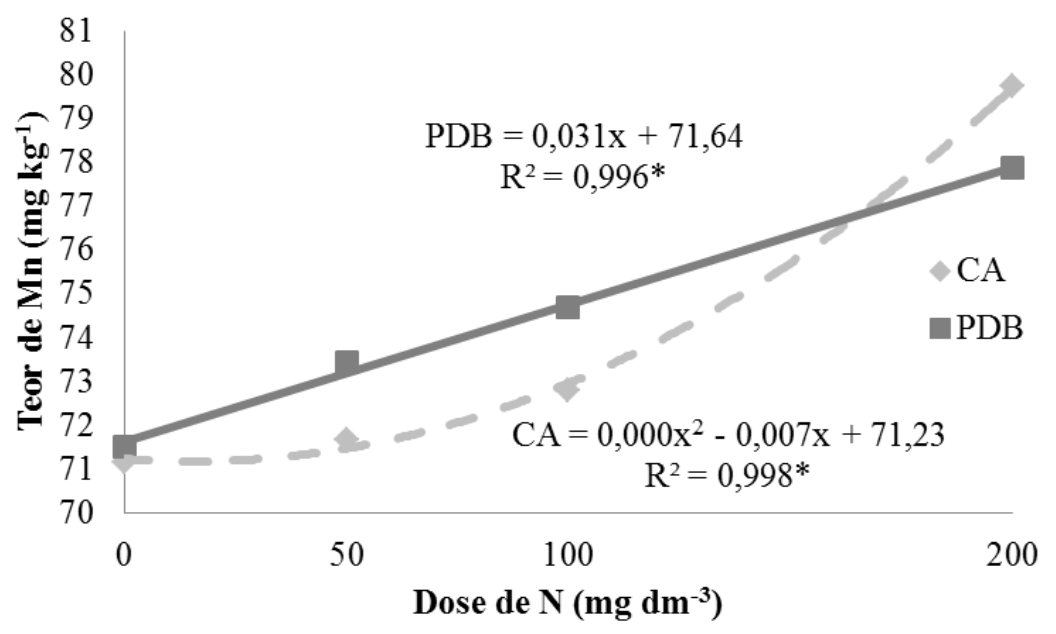


O resíduo orgânico, pó de balão, proporcionou maior teor de $\mathrm{Fe}(178,80 \mathrm{mg}$ $\left.\mathrm{kg}^{-1}\right)$, na parte aérea da gramínea Mombaça, que a cama de aviário (150,02 $\mathrm{mg} \mathrm{kg}^{-1}$ ). Esse comportamento pode ser devido à composição de cada resíduo utilizado, considerando-se que o pó de balão possui cerca de dez vezes mais esse micronutriente. $\mathrm{O}$ teor de $\mathrm{Zn}$ apresentou efeito quadrático significativo $(\mathrm{p}<0,05)$, somente com relação às doses de $\mathrm{P}_{2} \mathrm{O}_{5}$ utilizadas (Gráfico 7). Com relação ao teor de Zn, na parte aérea da gramínea, verificase elevação quadrática, até a dose de $\mathrm{P}_{2} \mathrm{O}_{5}$ $\left(100 \mathrm{mg} \mathrm{dm}^{-3}\right)$, entretanto, todas as doses de $\mathrm{P}_{2} \mathrm{O}_{5}$ proporcionaram teores de $\mathrm{Zn}$ superiores ao nível mínimo de suficiência para bovinos $\left(20 \mathrm{mg} \mathrm{kg}^{-1}\right)$, descrita por Mc Dowell et al. (1983). Entretanto, conforme a composição de metais pesados no solo e forragem deste trabalho, os valores determinados de $\mathrm{Zn}$ não proporcionam toxidez, pois estão abaixo do valor de referência definido pelo CONAMA (2009).

Gráfico 7 - Teor médio de $\mathrm{Zn}\left(\mathrm{mg} \mathrm{kg}^{-1}\right)$ na matéria seca de Panicum maximum cv. Mombaça, submetido a diferentes doses de $\mathrm{P}_{2} \mathrm{O}_{5}$, em Belém, Pará.

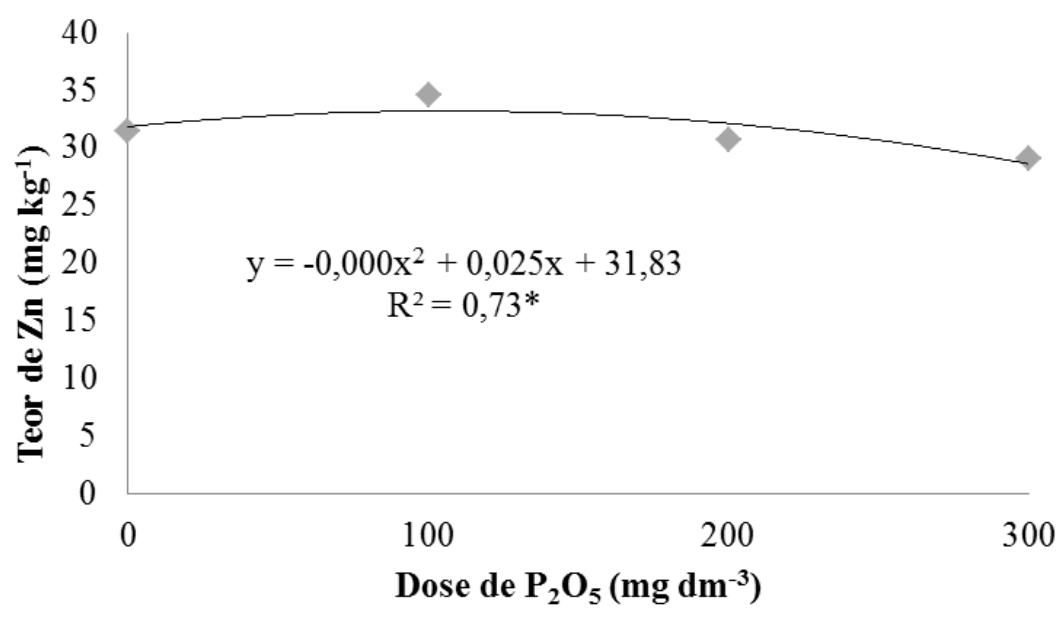

Observa-se que a variável MS apresentou efeito significativo $(\mathrm{p}<0,05)$, quanto aos resíduos orgânicos utilizados e dose de N. Os resíduos cama de aviário e pó de balão proporcionaram, respectivamente, teores de MS de 20,33 e $14,84 \mathrm{~g} \mathrm{vaso}^{-1}$. Santana et al. (2010) registraram teores de MS no Mombaça, em diferentes fontes e doses de corretivo de acidez, entre 20,48 e 45,10 g vaso $^{-1}$. Houve efeito significativo das doses de $\mathrm{N}$, no teor de MS da gramínea (Gráfico 8).

Independentemente do resíduo orgânico utilizado, houve aumento 
quadrático no teor de MS, com elevação das doses de $\mathrm{N}$, com teor máximo de matéria seca (19\%), na aplicação de 200 $\mathrm{mg} \mathrm{dm}{ }^{-3}$ de N. Em geral, os teores de MS estão abaixo dos encontrados por Santos et al. (2003), de 20,8\% e 20,6\%, respectivamente, para Tanzânia e Mombaça, aos 30 dias de crescimento. $\mathrm{O}$ baixo teor de MS, provavelmente, está associado à frequência de corte utilizada, de 30 dias, e, também, por ser trabalho em casa de vegetação, com cultivo das plantas em vasos, onde ocorre menor desenvolvimento das plantas, quando comparadas às cultivadas em condições de campo.

Gráfico 8 - Teor médio de MS (\%) na gramínea Panicum maximum cv. Mombaça, em função da aplicação de doses de nitrogênio, em Belém, Pará.

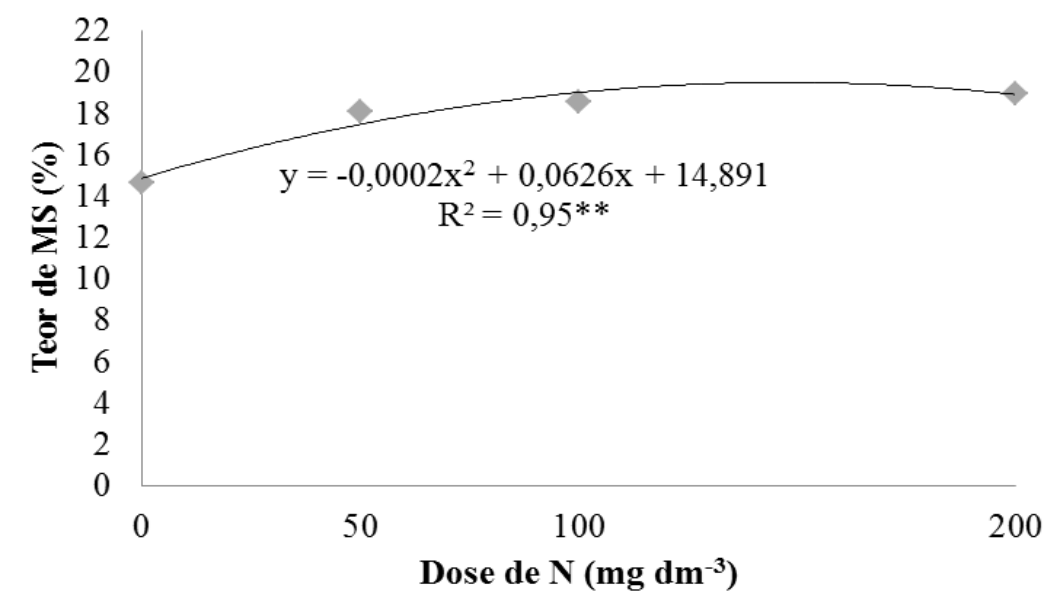

O teor de MO na gramínea apresentou efeito significativo $(\mathrm{p}<0,05)$ dos resíduos orgânicos, com o pó de balão superior à cama de aviário, respectivamente, 92,52 e 91,91\%. Em solos tropicais e subtropicais, altamente intemperizados, a MO tem grande importância no fornecimento de nutrientes às culturas, na retenção de cátions, complexação de elementos tóxicos e microminerais, estabilidade da estrutura, infiltração e retenção de água, aeração e atividade e diversidade microbiana, constituindo-se, assim, um componente fundamental da sua capacidade produtiva. Nessas regiões, a degradação da matéria orgânica, em condições inadequadas de manejo, é rápida e vem acompanhada de processo de deterioração das características químicas, físicas e biológicas do solo (BAYER; MIELNICZUK, 2008).

$\mathrm{O}$ teor de $\mathrm{MM}$ foi influenciado significativamente $(\mathrm{p}<0,05)$ pelos resíduos orgânicos utilizados, com a cama de aviário superior ao pó de balão, 8,09 e 
$7,48 \%$, respectivamente. Observa-se que à medida que aumentou o teor de MO da gramínea, com pó de balão, diminuiu o teor de matéria mineral e vice-versa, com cama de aviário.

$O$ teor de PB na gramínea foi influenciado significativamente $(\mathrm{p}<0,05)$ pelas doses de $\mathrm{P}_{2} \mathrm{O}_{5}$ (Gráfico 9). Com aumento das doses de $\mathrm{P}_{2} \mathrm{O}_{5}$, aumentou linearmente o teor de $\mathrm{PB}$, onde a maior dose de $\mathrm{P}_{2} \mathrm{O}_{5}\left(300 \mathrm{mg} \mathrm{dm}^{-3}\right)$ elevou o teor de PB para 11,57\%. Estudos com gramíneas tropicais evidenciaram que a adubação fosfatada aumenta significativamente a concentração de PB da parte aérea das plantas (SAWAN et al., 2001; FRANCO, 2003), devido ao maior sistema radicular proporcionado pela nutrição com fósforo (PATÊS et al., 2008). Em gramíneas forrageiras tropicais, teores de PB inferiores a $7 \%$ ou $1,12 \%$ de $N$, na MS, reduzem o consumo animal (MAZZA et al., 2009). Os níveis de PB da gramínea Mombaça, neste trabalho, estão adequados para bom funcionamento da microbiota ruminal e para alimentação dos ruminantes (VAN SOEST, 1994). Dias et al. (2007), ao avaliarem a gramínea Mombaça, adubada com diferentes fontes de fósforo, determinaram teor de PB de 7,75\%.

Gráfico 9 - Teor médio de PB (\% na MS) na gramínea Panicum maximum cv. Mombaça, submetido a diferentes doses de $\mathrm{P}_{2} \mathrm{O}_{5}$, em Belém, Pará.

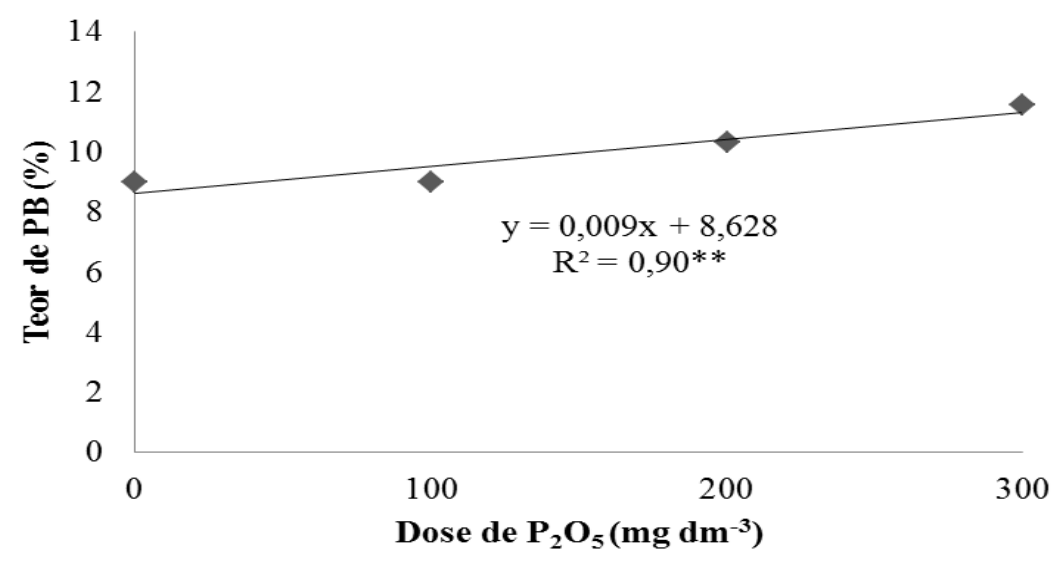

Os efeitos dos resíduos orgânicos utilizados, doses de $\mathrm{N}$ e $\mathrm{P}_{2} \mathrm{O}_{5}$ não foram significativos $(p>0,05)$ no teor de FDN, entretanto ao adubar com PDB e CA, os teores de FDN obtidos foram 61,05 e $62,20 \%$, respectivamente. O teor de FDA foi influenciado pela adubação fosfatada, com resposta quadrática positiva, à medida que aumentou a dose de $\mathrm{P}_{2} \mathrm{O}_{5}$ (Gráfico 10). A elevação da dose de $\mathrm{P}_{2} \mathrm{O}_{5}$ aumentou o teor de FDA na parte aérea da gramínea Mombaça, com teor de $36,86 \%$, na maior 
dose $\left(300 \mathrm{mg} \mathrm{dm}^{-3}\right)$. O baixo valor nutritivo das forrageiras tropicais é frequentemente mencionado na literatura e está associado ao reduzido teor de PB e minerais, e conteúdo de fibras elevado. Com o amadurecimento da planta, a produção de componentes potencialmente digeríveis - carboidratos solúveis, proteínas, minerais e outros conteúdos celulares - tende a decrescer. $\mathrm{O}$ alto teor de FDA indica maior proporção dos constituintes fibrosos mais resistentes à digestão, tais como as pentosanas resistentes, lignina e cutina, que são componentes da parede celular responsáveis pela baixa digestibilidade da forragem (VAN SOEST, 1994; EUCLIDES, 2000). Os valores observados são inferiores aos de Freitas et al. (2007) e Garcia et al. (2009), com teores médios de FDA, respectivamente, de $46,8 \%$ e $55,07 \%$.

Gráfico 10 - Teor médio de FDA (\% na MS) na gramínea Panicum maximum cv. Mombaça, submetido a diferentes doses de $\mathrm{P}_{2} \mathrm{O}_{5}$, em Belém, Pará.

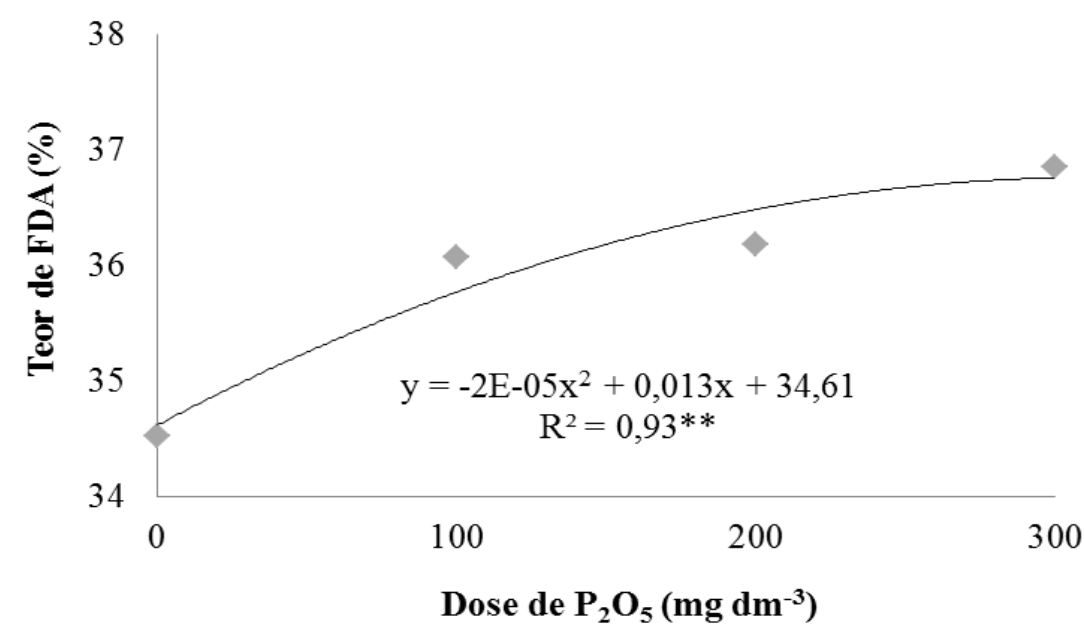

O teor de lignina na gramínea foi influenciado significativamente $(\mathrm{p}<0,05)$ pelas doses de $\mathrm{P}_{2} \mathrm{O}_{5} \quad$ (Gráfico 11). Semelhante ao teor de FDA, com aumento nas doses de $\mathrm{P}_{2} \mathrm{O}_{5}$, ocorreu elevação da lignina. A maior dose de $\mathrm{P}_{2} \mathrm{O}_{5}\left(300 \mathrm{mg} \mathrm{dm}^{-}\right.$ ${ }^{3}$ ) proporcionou teor de lignina de $6,88 \%$ na gramínea. Os dados de lignina do presente trabalho foram superiores aos de Martuscello (2007), em Panicum maximum, entre 2,19 e $4,18 \%$. A lignina afeta a digestibilidade da MS, principalmente da fração FDN, ao limitar a digestão da parede celular das plantas, e, nesse caso, há reflexo direto na concentração de energia digestível das 
plantas, o que compromete a produção animal (RODRIGUES; VIEIRA, 2006). De acordo com Eastridge (1997), a digestibilidade de um alimento está mais relacionada com a FDA do que com a FDN. A lignina limita a digestibilidade da forragem, por proporcionar resistência física à forrageira (JERBA et al., 2005). A lignina tem função duplicada contra herbivoria, pois age quimicamente como bloqueio enzimático e fisicamente, proporciona rigidez à parede celular (VAN SOEST, 1994; TAIZ; ZEIGER, 2004). A lignina, formada por precursores fenólicos, também, constitui fator anti-nutricional, pois, em geral, se liga quimicamente aos carboidratos da parede celular e constitui o principal obstáculo na digestão da fibra (JUNG et al., 1997).

Gráfico 11 - Teor médio de lignina (\% na MS) na gramínea Panicum maximum cv. Mombaça, submetido a diferentes doses de $\mathrm{P}_{2} \mathrm{O}_{5}$, em Belém, Pará.

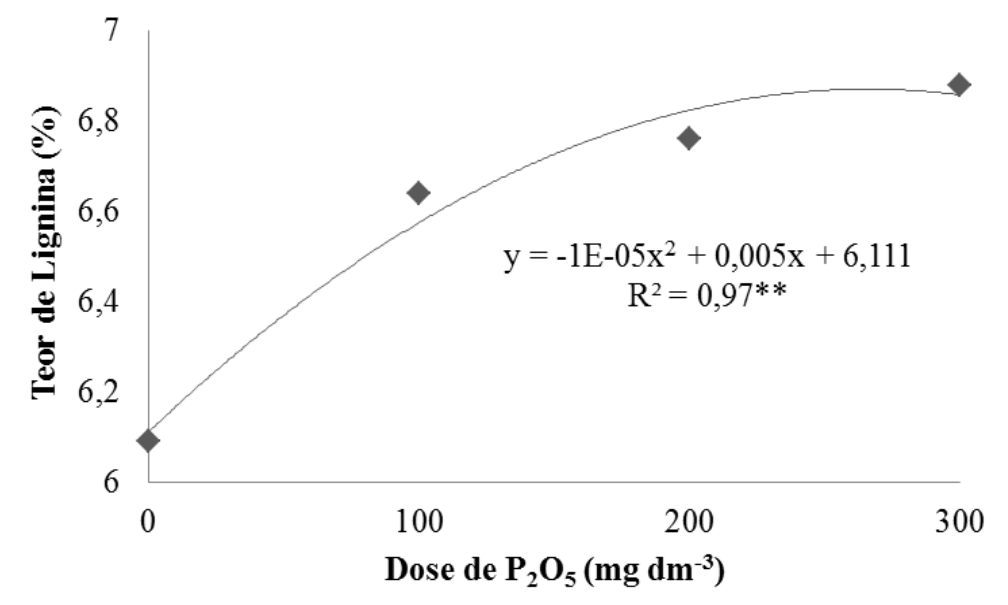

O teor de celulose na gramínea apresentou efeito significativo $(\mathrm{p}<0,05)$ com a aplicação das doses de $\mathrm{P}_{2} \mathrm{O}_{5}$ (Gráfico 12). Verifica-se que a aplicação de $\mathrm{P}_{2} \mathrm{O}_{5}$ influenciou negativamente no teor de celulose da gramínea, cujo maior teor esteve associado à dose de $300 \mathrm{mg} \mathrm{dm}^{-3}$. Não é recomendável ter como referência apenas o valor quantitativo de celulose, pois sua disponibilidade nutricional varia de indigestível a completamente digestível, na dependência do grau de lignificação (VAN SOEST, 1994). Os teores obtidos no presente trabalho são superiores aos de Maranhão et al. (2009). O teor de hemicelulose na gramínea não apresentou efeito significativo $(p>0,05)$ quanto às fontes de variância analisadas. 
Gráfico 12 - Teor médio de celulose (\% na MS) na gramínea Panicum maximum cv. Mombaça, submetido a diferentes doses de $\mathrm{P}_{2} \mathrm{O}_{5}$, em Belém, Pará.

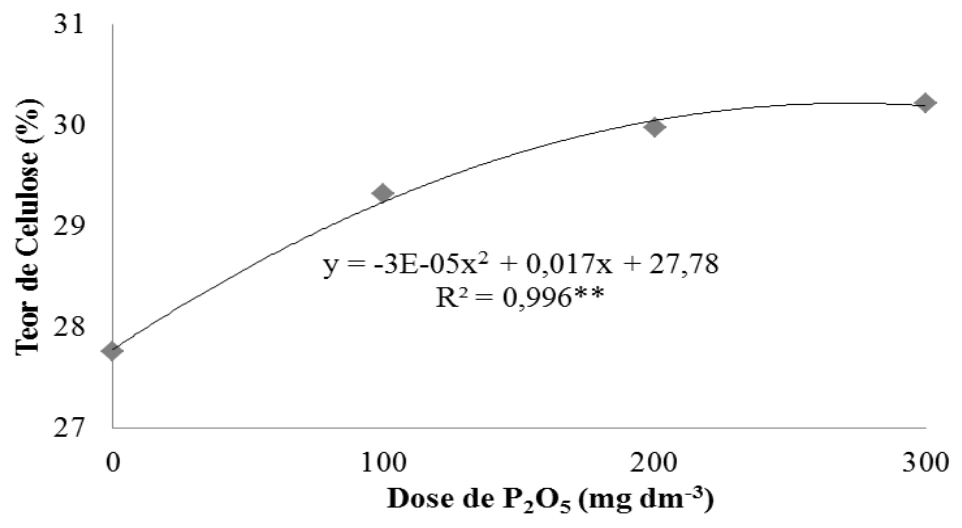

\section{CONCLUSÕES}

A combinação dos resíduos orgânicos com dose de nitrogênio, principalmente com resíduo pó de balão, apresentou influência significativa nos teores de macrominerais $(\mathrm{N}, \mathrm{P}$ e $\mathrm{K})$ e micromineral $(\mathrm{Mn})$.

O resíduo orgânico, pó de balão, serve como alternativa de adubação de pastagens, entretanto, torna-se contaminante do solo e da forragem devido à presença de metais pesados em sua composição, este fato pode ser limitante ao seu uso agrícola como adubo orgânico. Sugere-se assim, continuidade da pesquisa quanto ao teor de metais pesados.

\section{REFERÊNCIAS}

ALBUQUERQUE, A. Pólo estimula o reflorestamento. Revista

Pólo
ANDRADE, A. C.; FONSECA, D. M.; GOMIDE, J. A.; ALVAREZ, V. H.; MARTINS, C. E.; SOUZA, D. P. H. Produtividade e valor nutritivo do capimelefante cv. Napier sob doses crescentes de nitrogênio e potássio. Revista Brasileira de Zootecnia, v. 29, n. 6, p. 1589-1595, Nov./Dec. 2000.

ASSOCIATION OF OFFICIAL ANALYTICAL CHEMISTRY - AOAC. Official methods of analysis. 16. ed. Arlington: AOAC International, 1997.

BAYER, C.; MIELNICZUK, J. Dinâmica e função da matéria orgânica. In: SANTOS, G. A.; SILVA, L. S.; CANELLAS, L. P.; CAMARGO, F. A. O. (Eds.) Fundamentos da matéria orgânica do solo: ecossistemas tropicais e subtropicais. Porto Alegre: Metrópole, 2008. p. 7-18.

CAIRES, E. F.; FONSECA, A. F.; FELDHAUS, I. C.; BLUM, J. Crescimento radicular e nutrição da soja cultivada no sistema plantio direto em resposta ao calcário e gesso na superfície. Revista Brasileira de Ciência do Solo, v. 25, n. 4, p.1029-1040, 2001.

Sustentável, Belém, mar./abr. 2008. 
CECATO, U.; PEREIRA, L. A. F.; JOBIM, C. C.; MARTINS, E. N.; BRANCO, A. F.; GALBEIRO, S.; MACHADO, A. O. Influência das adubações nitrogenada e fosfatada sobre a composição químico-bromatológica do capim Marandú (Brachiaria brizantha (Hochst) Stapf cv. Marandú). Acta Scientiarum. Animal Sciences, v. 26, n. 3, p. 409-416, 2004.

CIOTTA, M. N.; BAYER, C.; ERNANI, P. R.; FONTOURA, S. M. V.; WOBETO, C.; ALBUQUERQUE, J. A. Manejo da calagem e os componentes da acidez de Latossolo Bruno em plantio direto. Revista Brasileira de Ciência do Solo, v. 28, n. 2, p. 317-326, Mar./Apr. 2004.

CONSELHO NACIONAL DO MEIO AMBIENTE (CONAMA). Resolução $\mathrm{n}^{\circ}$ 420, de 28 de dezembro de 2009. "Dispõe sobre critérios e valores orientadores de qualidade do solo quanto à presença de substâncias químicas e estabelece diretrizes para o gerenciamento ambiental de áreas contaminadas por essas substâncias em decorrência de atividades antrópicas. Diário Oficial [da República Federativa do Brasil], Brasília, DF, $\mathrm{n}^{\circ}$ 249, de 30/12/2009, p. 81-84. Também disponível em http://www.mma.gov.br/port/conama/legia no1.cfm?codlegitipo=3\&ano=2009.

Acesso em: 10/01/2011.

COSTA, N. L. Adubação nitrogenada e consorciação de capim elefante (Pennisetum purpureum cv. Cameroon) com leguminosas forrageiras tropicais. Pesquisa Agropecuária Brasileira, v. 30, n. 3, p. 401-408, mar. 1995.

COSTA, K. A. P.; OLIVEIRA, I. P.; FRANÇA, A. F. S. GUIMARÃES, T. E. R. Teores de PB, MS, FDN e FDA na forragem de Panicum maximum cv. Tanzânia em função da aplicação de doses de nitrogênio, potássio e enxofre. In: REUNIÃO ANUAL DA SOCIEDADE
BRASILEIRA DE ZOOTECNIA, 40., Santa Maria. Anais... Santa Maria, 2003. CD ROM.

DIAS, F. J.; JOBIM, C. C.; CECATO, U.; BRANCO, A. F.; SANTELlO, G. A. Composição química da gramínea Mombaça (Panicum maximum Jacq. cv. Mombaça) adubado com diferentes fontes de fósforo sob pastejo. Acta Scientiarum. Animal Science, v. 29, n. 1, p. 9-16, Nov./Dec. 2007.

EASTRIDGE, M. L. Fibra para vacas leiteiras. In: SIMPÓSIO SOBRE PRODUÇÃO ANIMAL CONFINAMENTO DE BOVINOS, 9., Piracicaba. Anais ... Piracicaba, 1997. p. 33-50.

EMBRAPA (SNLCS). Serviço Nacional de Levantamento e Conservação de Solos. Manual de métodos e análise de solo. 2 ed. Rio de Janeiro: EMBRAPA Solos, 1997.

EUCLIDES, V. P. B. Intensificação da produção de carne bovina em pastagem. 2000. Disponível em: http://www.cnpgc.embrapa.br/publicacoes/ naoseriadas/cursosuplementacao/manejo/2. html. Acesso em: 10 novembro 2010.

FRANCO, C. J. H. Avaliação agronômica de fontes e doses de fósforo pra o capimTifton 85. 2003. 92p. Dissertação (Mestrado em Agronomia) - Faculdades de Ciências Agrárias e Veterinárias, Jaboticabal, 2003.

FREITAS, K. R.; ROSA, B.; RUGGIERO, J. A.; NASCIMENTO, J. L.; HEINEMAM, A. B.; FERREIRA, P. H.; MACEDO, R. Avaliação da gramínea Mombaça (Panicum maximum Jacq.) submetido a diferentes doses de nitrogênio. Acta Scientiarum Agronomy, v. 27, n. 1, p. 83-89, jan./mar. 2005. 
FREITAS, K. R.; ROSA, B.; RUGGIERO, J. A.; NASCIMENTO, J. L.; HEINEMAM, A. B.; MACEDO, R. F.; NAVES, M. A. T.; OLIVEIRA, I. P. Avaliação da composição químico bromatológica da gramínea Mombaça (Panicum maximum jacq.) submetido a diferentes doses de nitrogênio. Bioscience Journal, v. 23, n. 3, p. 1-10, 2007.

GARCIA, A. R.; ALVAREZ, W. F. M.; COSTA, N. A.; NAHÚM, B. S.; NETO, T. Q.; CASTRO, S. R. S. Avaliação do desempenho de bovinos de corte criados em sistemas silvipastoris no estado do Pará. Amazônia: Ciência \& Desenvolvimento, v. 4, n. 8, p. 51-62, jan./jun. 2009.

JERBA, V. F.; FERNANDES, C. D.; MARCHI, C. E.; LEANDRO, K. R.; OLIVEIRA, V. B. Identificação dos fatores de anti-qualidade em folhas dos gêneros Brachiaria e Panicum. In: CONGRESSO BRASILEIRO DE ZOOTECNIA, 7., Campo Grande. Anais... Campo Grande, 2005. CD Rom.

JUNG, H. G.; MERTENS, D. R.; PAYNE, A. J. Correlation of acid detergent lignin and klason lignin with digetibility of forage dry matter and neutral detergent fiber. Journal of Dairy Science, v. 80, p.1622-1628, Aug. 1997.

LAVRES JÚNIOR, J. Combinações de doses de nitrogênio e potássio para a gramínea Mombaça. 2001. 103 f. Dissertação (Mestrado em Solos e Nutrição de Plantas) - Escola Superior de Agricultura Luiz de Queiroz, Piracicaba, 2001.

MACEDO, M. C. M. Sistemas de produção animal em pasto nas savanas tropicais da América: limitações à sustentabilidade. In: REUNIÓN LATINOAMERICANA DE PRODUCCIÓN ANIMAL, 16., CONGRESO URUGUAYO DE
PRODUCCIÓN ANIMAL, 3., 2000, Montevideo. Anales ... Montevideo: Alpa, 2000. Compact disc.

MALAVOLTA, E.; VITTI, G. C.; OLIVEIRA, S. A. Avaliação do estado nutricional das plantas: princípios e aplicações. 2. ed. Piracicaba: POTAFOS, 1997.

MANARIN, C. A.; MONTEIRO, F. A. Nitrogênio na produção e diagnose foliar da gramínea Mombaça. Boletim de Indústria Animal, v. 59, n. 2, p. 115123, 2002.

MARANHÃO, C. M. A.; SILVA, C. C. F.; BONOMO, P.; PIRES, A. J. V. Produção e composição químico-bromatológica de duas cultivares de braquiária adubadas com nitrogênio e sua relação com o índice SPAD. Acta Scientiarum Animal Sciences, v.31, n. 2, p. 117-122, 2009.

MARTha JÚNIOR, G. B. Produção de forragem $\mathrm{e}$ transformações do nitrogênio do fertilizante em pastagem irrigada de capim Tanzânia. 2003. 149 f. Tese (Doutorado em Agronomia) - Escola Superior de Agricultura Luiz de Queiroz, Piracicaba, 2003.

MARTUSCELLO, J. A. Repetibilidade e seleção em Panicum maximum Jacq. 2007. 100 f. Tese (Doutorado em Zootecnia) - Universidade Federal de Viçosa, Viçosa, 2007.

MAZZA, L. M.; PÔGGERE, G. C.; FERRARO, F. P.; RIBEIRO, C. B.; CHEROBIM, V. F.; MOTTA, A. C. V.; MORAES, A. Adubação nitrogenada na produtividade e composição química da gramínea Mombaça no primeiro planalto paranaense. Scientia Agraria, v.10, n.4, p.257-265, 2009.

MC DOWELL, L. R.; CONRAD, L. R. H.; ELLIS, G. L.; LOOSLI, K. Minerals for 
grazing ruminants in tropical regions. Gainesville : University of Florida, 1983.

MELLO, S. Q. S.; FRANÇA, A. F. S.; LANNA, A. C.; HINE, A. F. B.; KLIMANN, H. J.; RIOS, L. C.; SOARES, T. V. Adubação nitrogenada em capimmombaça: produção, eficiência de conversão e recuperação aparente do nitrogênio. Ciência Animal Brasileira, v. 9, n. 4, p. 935-947, 2008.

NATIONAL RESEARCH COUNCIL (NRC). Nutrients requeriment of sheep. $6^{\text {th }}$ ed. Washington: National Academy Press, 1985. p. 2-3.

\section{Nutrient requirements of beef} cattle. $7^{\text {th }}$ ed. Washington: National Academy of Science, 2000. 242 p. (Nutrient Requeriments of Domestic Animals, 4).

\section{Nutrient Requirements of Dairy}

Cattle. $7^{\text {th }}$ ed. Washington: National Academy of Sciences, 2001.

PATÊS, N. M. S.; PIRES, A. J. V.; CARVALHO, G. G. P.; OLIVEIRA, A. C.; FONSÊCA, M. P.; VELOSO, C. M. Produção e valor nutritivo do capimtanzânia fertilizado com nitrogênio e fósforo. Revista Brasileira de Zootecnia, v. 37, n. 11, p. 1934-1939, Nov. 2008.

RAIJ, B. V. Fertilidade do solo e adubação. 2. ed. Piracicaba: Ceres, 1991.

RIBEIRO, E. G.; FONTES, C. A. A.; BERGOTTINI, J. G.; PALIERAQUI, A. C. C.; MARTINS, C. E.; SILVA, R. C. Influência da irrigação, nas épocas seca e chuvosa, na produção e composição química dos capins napier e Mombaça em sistema de lotação intermitente. Revista Brasileira de Zootecnia, v. 38, n. 8, p.1432-1442, Aug. 2009.

RODRIGUES, M. T. ; VIEIRA, R. Metodologias aplicadas ao fracionamento de alimentos. In: BERCHIELLI, T. T. ; PIRES, A. V. ; OLIVEIRA, S. G. (Ed.). Nutrição de Ruminantes. Jaboticabal: Funep, 2006. p.25- 56.

SANTANA, G. S.; BIANCHI, P. P. M.; MORITA, I. M.; ISEPON, O. J.; FERNANDES, F. M. Produção e composição bromatológica da forragem da gramínea Mombaça (Panicum maximum Jacq.), submetidos a diferentes fontes e doses de corretivo de acidez. Semina: Ciências Agrárias, Londrina, v.31, n.1, p.241-246, jan./mar. 2010.

SANTOS, M. V. F.; DUBEUX JÚNIOR, J. C. B.; SILVA, M. C. SANTOS, S. F.; FERREIRA, R. L. C.; MELLO, A. C. L., FARIAS, I.; FREITAS, E. V. Produtividade e composição química de gramíneas tropicais na Zona da Mata de Pernambuco. Rev. Bras. Zootec., v. 32, n. 4, p.821-827, July/Aug. 2003.

SANTOS, E. M; ZANINE, A. M; FERREIRA, D. J; OLIVEIRA, J. S; PEREIRA, O. G. Composição química do feno de capim-tanzânia (Panicum maximum) tratado com hidróxido de sódio. Arquivo de Ciência Veterinária e Zoologia, v.11, n.1, p.41-46, 2008.

SANTOS JÚNIOR, J. D. G. Fertilidade do solo no acúmulo de forragem e nutrição do capim-Tanzânia sob pastejo na região dos Cerrados. 2005. 105 f. Tese (Doutorado em Solos e Nutrição de Plantas) - Escola Superior de Agricultura “Luiz de Queiroz", Piracicaba. 2005.

SARRUGE, J. R.; HAAG, H. P. Análise química em plantas. Piracicaba: ESALQ, Departamento de Química, 1974.

SAWAN, Z. M.; HAFEZ, S. A.; BASYONY, A. E. Effect of phosphorus fertilization and foliar application of chelate zinc and calcium on seed, protein and oil yields and oil properties of cotton. Journal Agriculture Science, v.136, p.191-198, 2001. 
SHUNKE, R. M. Alternativas de manejo de pastagem para melhor aproveitamento do nitrogênio do solo. Campo Grande: Embrapa - CNPGC, 2001 (Embrapa - CNPGC. Documentos 111).

SILVA, S. C. Condições edafo-climáticas para a produção de Panicum sp. In: SIMPÓSIO SOBRE MANEJO DA PASTAGEM, 12., 1995, Piracicaba. Anais... Piracicaba: Fealq, 1995. p.129146.

SILVA, D. J.; QUEIROZ, A. C. Análise de Alimentos (métodos químicos e biológicos). 3. ed. Viçosa: Ed. da UFV, 2002.
SILVEIRA, C. P.; MONTEIRO, F. A. Macrominerais em folhas diagnósticas do capim-tanzânia adubado com nitrogênio e cálcio. Revista Brasileira de Zootecnia, v.39, n.4, p.736-745, 2010.

TAIZ, L.; ZEIGER, E. Fisiologia vegetal. 3. ed. Porto Alegre: Artmed, 2004.

VAN SOEST, P. J. Methods for dietary fiber, neutral detergent fiber, and non starch polyssacarides in relation to animal nutrition. Journal Dairy Science, v.74, n.10, p.3583-3597, 1994. 